(2014). Critical Factors in Data Governance for Learning Analytics. Journal of Learning Analytics, 1(3), 211-222.

\title{
Critical Factors in Data Governance for Learning Analytics
}

\author{
Noureddine Elouazizi \\ Faculty of Science's Teaching and Learning Centre, University of British Columbia \\ Centre for Teaching and Learning Technologies, University of British Columbia \\ Vancouver, British Columbia
}

\begin{abstract}
This paper identifies some of the main challenges of data governance modelling in the context of learning analytics for higher education institutions, and discusses the critical factors for designing data governance models for learning analytics. It identifies three fundamental common challenges that cut across any learning analytics data governance model, viz., the ownership of the learning analytics data sets, the interpretation of the data, and the decision making based on the data. It also proposes a set of high-level requirements necessary for modelling data governance for learning analytics.
\end{abstract}

Keywords: Data, governance, analytics, learning

\section{INTRODUCTION}

This paper contributes to the field of learning analytics from the perspective of learning analytics data governance modelling. I start by laying the groundwork for the idea that the potential for conflict regarding the information assets provided by learning analytics is a major threat to formulating and implementing learning analytics in general and learning analytics data governance in particular. Then, I propose that to increase the chances of success for a learning analytics initiative, it is necessary to design learning analytics data governance models that narrow the zones of potential conflict among stakeholders and increase the shared common-ground perspectives on the added value of learning analytics. To support the formulation of such learning analytics data governance models, the paper identifies three critical factors that must be considered and suggests a set of high-level requirements to guide the formulation of learning analytics data governance.

The paper is structured into five sections. Section 2 discusses and defines learning analytics. Section 3 discusses general data management and governance as well as institutional governance models, showing that encompassing definitions of institutional/university governance and general data management lend themselves to broader interpretations by different stakeholders, resulting in potential zones of conflict and exhibiting the power dynamics of stakeholder control vs. stakeholder accountability. Section 4 identifies common challenges in learning analytics data governance, viz., the ownership of the learning analytics data sets, the interpretation of the data, and the decision making based on the data. This section also offers suggestions for a way forward in modelling data governance in the context of learning analytics. Section 5 calls for the need to integrate learning analytics data governance with sense-making frameworks and with ethical frameworks. 


\section{DEFINING LEARNING ANALYTICS AND GOVERNANCE}

Previous studies have constructed a set of metrics for measuring the levels of maturity and the risks associated with the implementation of learning analytics within the context of educational institutions (Campbell, Deblois, \& Oblinger, 2007; Davenport, Harris, \& Morrison, 2010; Bichsel, 2012; Stiles, 2012). In these studies, the governance of learning analytics is considered one of the critical components for consideration in the design and successful implementation of learning analytics. This increasing awareness of the role of governance in learning analytics is the by-product of the view that data sets (as information assets) can, if used properly, empower many aspects of the ecosystem of an educational institution. However, this view is largely idealized for two main reasons: a) information assets are often the worst governed, least understood, and most poorly utilized key asset; and b) information assets are dynamic in nature, multifaceted, and increase exposure to security and privacy risks (Slade \& Prinsloo, 2013).

The term Learning Analytics, as defined by the Society for Learning Analytics Research (SOLAR), refers to "the measurement, collection, analysis and reporting of data about learners and their contexts, for purposes of understanding and optimizing learning and the environments in which it occurs" (2011, p. 4). ${ }^{1}$ This definition covers the life cycle of learning analytics and its contexts and lends itself to broader interpretations by different stakeholders of learning analytics, especially when coupled with other segmented definitions of learning analytics. Other segmented definitions of learning analytics include definitions that focus on processes and activities (Brown, 2011), on purpose (Ferguson, 2012), and on distinguishing learning analytics from academic analytics and educational data mining (Long \& Siemens, 2011; Siemens \& Baker, 2012). The way learning analytics is defined above is encompassing, covers different forms (data sets) and functions (uses), works as a cohesive and integrated whole, and is intended to serve the needs of the academy at a variety of levels (van Barneveld, Arnold, \& Campbell, 2012). Perceived from a governance perspective, the more encompassing a definition is, the more potential there is for conflict over stakeholder control vs. stakeholder accountability. There are two main reasons for this. First, the nature of the design of the existing governance models within the context of higher education varies from one institution to another and these governance models may not be readily conducive to a culture of learning analytics (Macfadyen \& Dawson, 2012). Second, the primary driver for implementing learning analytics in many institutions is the cost-benefit/return-oninvestment perspective for implementing learning analytics, rather than issues of data use, management, and related ethical challenges (Bichsel, 2012, p. 13).

As such, the use and implementation of data governance for learning analytics in the context of higher education requires a shared understanding of the goals and purposes of learning analytics across

\footnotetext{
${ }^{1}$ The term has roots in different areas, viz., business intelligence (with its own roots in data warehousing, customer relationship management, and web intelligence), educational data mining (including but not limited to the mining of the learning and content management systems' user and usability data), and recommender systems. For an overview of the history of the emergence of the field of learning analytics, see, for example, Romero \& Ventura, 2006; Baepler \& Murdoch, 2010; Ferguson, 2012; Chatti, Dyckhoff, Schroeder, \& Thüs, 2012. 
(2014). Critical Factors in Data Governance for Learning Analytics. Journal of Learning Analytics, 1(3), 211-222.

different layers of the governance forms and structures. The diffusion of such shared understanding of these goals and functions may require modifying and adapting some aspects of the various governance models that exist at the educational institution (e.g., institutional governance, IT governance, etc.) to incorporate learning analytics.

\section{DATA GOVERNANCE AND INSTITUTIONAL (UNIVERSITY) GOVERNANCE}

Learning analytics data governance cannot be modelled in isolation from IT governance and institutional governance. With respect to IT governance, I assume, along the lines of Redman (1998) that the responsibility for data governance should be outside of the IT department since the parties that gain or lose the most by the quality of the data are departments/sections outside the IT department. With respect to learning analytics data, and as Ferguson observes, "significant amounts of learner activity take place externally [to the institution]... records are distributed across a variety of different sites with different standards, owners and levels of access" (2012, p. 6). As such, data governance for learning analytics can overlap with IT governance at different levels but should not be collapsed under the umbrella of IT governance. However, the integration of learning analytics governance and institutional governance requires careful handling because the distribution of authority within the context of institutional governance can affect, in many respects, data governance for learning analytics.

Governance in the context of higher education is defined as "the process for distributing authority, power and influence for academic decisions among campus constituencies" (Alfred, 1998). These campus constituencies include the board of trustees, faculty, students, staff, administrators, the senate, and unions. The constituencies can also include additional committees or subcommittees with varying degrees of power and control. In terms of categorization, it is possible to distinguish between four types of university governance models, depending on the number of governing bodies. For example, in the context of university governance in Canadian higher education, it is possible to identify at least four models: unicameral governance models, bicameral governance models, tri-cameral governance models, and hybrid governance models (Jones, 1997). Table 1 illustrates the different governing bodies within the context of a higher education institution.

In educational institutions with a unicameral governance model, decision making is centralized. In educational institutions with a hybrid model, decision making can be distributed and the responsibility is shared among those affected by the decision. ${ }^{2}$ The dynamics and distribution of power and influence can differ significantly from one educational institution to another. None of the models of university governance identified in Table 1 can readily lend itself to the use of learning analytics without significantly altering parts of the existing governance processes, procedures, and policies. This is

\footnotetext{
${ }^{2}$ This same governance challenge is also observed in corporate contexts wherein at one end of the spectrum, the operational model of governance centrally controls the data, its interpretation, and the enacting of the strategic initiatives. It does not allow cross-organizational participation of all the stakeholders. At the other end of the spectrum, the constituency representational model for governance is too political and much more lopsided towards influencing decision making rather than structuring it. See Gill (2002) for discussion of governance models in the corporate world. 
(2014). Critical Factors in Data Governance for Learning Analytics. Journal of Learning Analytics, 1(3), 211-222.

because, on the one hand, the internal structure of these governance models is primarily determined by power structures rooted in political and economic drivers that may lie beyond internal governance within the university. On the other hand, the implementation of learning analytics requires an organizational capacity and readiness not always available without considerable cultural shifts within the institution about the added value of learning analytics (Macfadyen \& Dawson, 2012; Norris \& Baer, 2013). Henceforth, the design and implementation of a learning analytics data governance model requires careful handling for fitting it into the existing university governance models through superimposing new learning analytics-specific governance mechanisms that allow for an overlap between institutional governance and other related governance structures, such as IT governance.

Table 1: Governance Models at Universities

\begin{tabular}{|l|l|}
\hline Governance Model & Governing Bodies \\
\hline Unicameral & Single governing body (governs academia and administration) \\
\hline Bicameral & Governing board \\
\hline & Senate \\
\hline Tri-cameral & Governing board \\
\hline & Senate \\
\hline Hybrid & University council \\
\hline & President \\
\hline & Faculty council \\
\hline & Senate \\
\hline & University council \\
\hline
\end{tabular}

Additionally, the way the learning analytics data governance is modelled and implemented crucially depends on the general data management model in place. General data management is defined as "the set of processes that ensures that important data assets are formally managed throughout the enterprise" (Otto, 2011). Weber, Otto, and Österle (2009) define general data management and governance as the entire life cycle of decision rights and responsibilities regarding the management of data as information assets (See also Petersen, 2012). These definitions of general data management and governance converge on the need to define the (human and systems) entities that supply data, those that input data, those that process data, those that output data, and those that consume data. As is the case with the encompassing definition of learning analytics, the encompassing definition of data governance can also lend itself to broader interpretations by different stakeholders in general and learning analytics data governance in particular; henceforth they form an additional potential zone of conflict, exhibiting the power dynamics of stakeholder control vs. stakeholder accountability. This implies that in any learning analytics data governance model that an organization may end up adopting, there is a need to enable the use and adoption of learning analytics in such a way that balances the expectations and obligations of learning analytics stakeholders.

In the absence of carefully designed learning analytics data governance, learning analytics initiatives can fail to serve their functions. This is the case when the learning analytics data governance model is not 
(2014). Critical Factors in Data Governance for Learning Analytics. Journal of Learning Analytics, 1(3), 211-222.

entirely clear about who owns the physical learning analytics data, who owns the interpretation of the learning analytics data, and who owns the decision making based on learning analytics data. Hence, it is necessary to determine the main overlaps between the types of learning analytics data, data sources, and stakeholder groups. These overlaps are approximated in Table $2 .^{3}$

Table 2: Learning Analytics Stakeholders, Data Uses, and Data Sources Overlaps

\begin{tabular}{|c|c|c|}
\hline STAKEHOLDER GROUPS & AREAS FOR USING LEARNING ANALYTICS & SOURCES \& DATA TYPES ${ }^{4}$ \\
\hline $\begin{array}{l}\text { Faculty (may include } \\
\text { contracted faculty, } \\
\text { adjunct faculty) }\end{array}$ & $\begin{array}{ll}- & \text { Instructional practices } \\
- & \text { Action research } \\
- & \text { Assessment practices } \\
\text { - } & \text { Learning processes } \\
\text { - } & \text { Teaching effectiveness } \\
-\quad & \text { Teaching evaluation }\end{array}$ & $\begin{array}{l}\text { - } \quad \text { LMS \& CMS generated data: learning } \\
\text { content items that the students used } \\
\text { - } \quad \text { Student Information System (SIS) } \\
\text { generated data: student learning } \\
\text { plans, courses taken, etc. } \\
\text { - } \quad \text { Archives and historical data (covering } \\
\text { student information and teaching } \\
\text { evaluations) } \\
\text { - LMS \& CMS generated data: which } \\
\text { assessment items the students used } \\
\text { - LMS \& CMS generated data: student } \\
\text { participation rates in online } \\
\text { discussions } \\
\text { Additional analytics and visualization } \\
\text { tools generated data }\end{array}$ \\
\hline Students & $\begin{array}{ll}\text { - } & \text { Access to learning resources } \\
\text { - } & \text { Access to learning support } \\
\text { - } & \text { Self-monitoring of own } \\
& \text { academic progress }\end{array}$ & $\begin{array}{ll}\text { - } & \text { LMS \& CMS generated data: student } \\
\text { use of learning resources } \\
\text { - } \quad \text { Student Information System (SIS) } \\
\text { generated data: student self- } \\
\text { monitoring, planning, etc. } \\
\text { - } \quad \text { LMS \& CMS generated data: student }\end{array}$ \\
\hline
\end{tabular}

\footnotetext{
${ }^{3}$ Note that this is by no means an exhaustive listing of all the learning analytics data governance stakeholders. In general, learning analytics literature defines the various stakeholders as being the teachers, the learners, the institutions and their representatives, and leaves the set open for the inclusion of additional stakeholders (data subjects and data clients) (Greller \& Drachsler, 2012; Drachsler \& Greller, 2012). My underlying assumption in Table 2 is that the associations between learning analytics stakeholders and different learning analytics data sets and sources would depend on the institution's governance model, the general data management model, and the business processes and procedures in place. Furthermore, the categorization of data usages and stakeholder groups in this table does not imply that a given data set is always used exclusively by a given group of stakeholders. Data sets can be shared across groups of stakeholders, when deemed relevant, and there is no one-to-one relation between a data type and a category of stakeholder.

${ }^{4}$ Note that the sources of the data types that can form part of the learning analytics data governance can originate from different applications, including but not limited to the following: learning management systems (LMS), content management systems (CMS), student information systems (SIS), online exams \& assessment platforms, virtual learning environment personalized plug-ins (e.g., third-party software tools), enterprise reporting platforms (ERP), business intelligence platforms, and third-party administrative systems. Henceforth, the observations formulated within the context of this section cover the technology that gathers data about the learners in a learner-centric type of learning analytics, along the lines of Kruse and Pongsajapan (2012). In addition to the applications and systems referred to above, learning analytics data can also originate from offline (historical) data repositories and archives of teaching evaluations. When digitized, this data can be integrated and lend itself to automatic processing on equal footing as the data generated by the digital tracking systems and applications. The same extends to offline historical student information data. I am grateful to an anonymous reviewer for raising this issue.
} 
(2014). Critical Factors in Data Governance for Learning Analytics. Journal of Learning Analytics, 1(3), 211-222.

\begin{tabular}{|c|c|c|}
\hline & & $\begin{array}{l}\text { frequency of access to the LMS } \\
\text { - } \quad \text { Analytics tools generated data }\end{array}$ \\
\hline Researchers & $\begin{array}{ll}- & \text { Design-based research } \\
\text { - } & \text { Action-based research } \\
\text { - } & \text { Pedagogy research } \\
\text { - } & \text { Learning-related research }\end{array}$ & $\begin{array}{ll}- & \text { LMS \& CMS generated data } \\
\text { - } & \text { Student Information System (SIS) } \\
\text { generated data } \\
\text { - } \quad \text { Archives and historical data (covering } \\
\text { student information and teaching } \\
\text { evaluations) } \\
\text { - } \quad \text { Additional analytics and visualization } \\
\text { tools generated data } \\
\text { - } \quad \text { Enterprise systems generated data }\end{array}$ \\
\hline $\begin{array}{l}\text { Department heads/ } \\
\text { Program directors }\end{array}$ & $\begin{array}{ll}- & \text { Teaching effectiveness } \\
- & \text { Teaching evaluation } \\
- & \text { Program evaluation } \\
- & \text { Student flow-through } \\
- & \text { Student dropout rates \& failure } \\
- & \text { Student retention strategies }\end{array}$ & $\begin{array}{ll}- & \text { LMS \& CMS generated data } \\
\text { - } & \text { Student Information System (SIS) } \\
\text { generated data } \\
\text { - } \quad \text { Archives and historical data (covering } \\
\text { student information and teaching } \\
\text { evaluations) } \\
\text { - } \quad \text { Additional analytics and visualization } \\
\text { tools generated data } \\
\text { - ERP systems generated data }\end{array}$ \\
\hline Deans & $\begin{array}{ll}\text { - } & \text { Empowering education research } \\
\text { - } & \text { Enhancing reputation } \\
\text { - } & \text { Improving accountability }\end{array}$ & $\begin{array}{ll}\text { - } & \text { ERP systems: enrolment, retention } \\
\text { historical data, etc. } \\
\text { - } \quad \text { Student Information System (SIS) } \\
\text { generated data } \\
\text { - } \quad \text { Archives and historical data (covering } \\
\text { student information and teaching } \\
\text { evaluations) } \\
\text { - } \quad \text { Additional analytics and visualization } \\
\text { tools generated data } \\
\text { - CRM: customer relationship } \\
\text { management systems }\end{array}$ \\
\hline $\begin{array}{l}\text { Government and } \\
\text { policy makers }\end{array}$ & $\begin{array}{ll}\text { - } & \text { Improving accountability } \\
\text { - } & \text { Creating transparency } \\
\text { - } & \text { Assess impact of policy changes }\end{array}$ & $\begin{array}{ll}\text { - } & \text { ERP systems: enrollment, retention } \\
\text { - } & \text { historical data, etc. } \\
\text { Additional analytics and visualization } \\
\text { tools generated data } \\
\text { - } \quad \text { Student Information System (SIS) } \\
\text { generated data } \\
\text { - CRM: customer relationship } \\
\text { management systems }\end{array}$ \\
\hline $\begin{array}{l}\text { Community and } \\
\text { donors }\end{array}$ & $\begin{array}{ll}\text { - } & \text { Policy impact } \\
\text { - } & \text { Research impact } \\
\text { - } & \text { Educational outreach }\end{array}$ & $\begin{array}{l}\text { - } \quad \text { CRM: customer relationship } \\
\text { management systems }\end{array}$ \\
\hline Executive officers & $\begin{array}{ll}- & \text { Process optimization } \\
\text { - } & \text { Improving graduation rates }\end{array}$ & $\begin{array}{l}\text { - } \quad \text { ERP systems: enrolment, retention } \\
\text { historical data, etc. }\end{array}$ \\
\hline
\end{tabular}


(2014). Critical Factors in Data Governance for Learning Analytics. Journal of Learning Analytics, 1(3), 211-222.

\begin{tabular}{|c|c|c|}
\hline & $\begin{array}{ll}\text { - } & \text { Improving retention rates } \\
\text { - } & \text { Empowering education research } \\
\text { - } & \text { Enhancing reputation } \\
\text { - } & \text { Improving accountability }\end{array}$ & 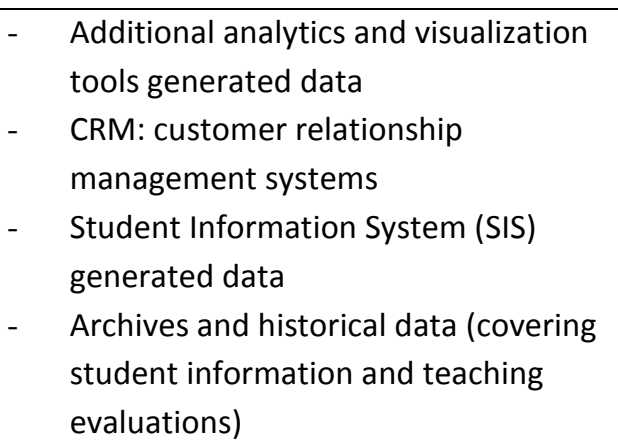 \\
\hline $\begin{array}{l}\text { Learning systems } \\
\text { staff }\end{array}$ & $\begin{array}{ll}\text { - } & \text { User experience } \\
\text { - } & \text { System usability } \\
\text { - } & \text { Systems performance }\end{array}$ & $\begin{array}{l}\text { - } \\
\text { CMS: user logs of time spent in } \\
\text { different areas of the system } \\
\text { - } \text { LMS: user clicks on different content } \\
\text { items and the time spent on each } \\
\text { page } \\
\text { - Backend application servers: event } \\
\text { logs, system response, load time, } \\
\text { disaster recovery time } \\
\text { - Additional analytics and visualization } \\
\text { tools generated data }\end{array}$ \\
\hline $\begin{array}{l}\text { Learning content } \\
\text { staff }\end{array}$ & $\begin{array}{ll}- & \text { Instructional design } \\
- & \text { Content layout and design } \\
- & \text { Interface design }\end{array}$ & $\begin{array}{l}\text { - } \\
\text { CMS: content and system areas used } \\
\text { by learners; content items viewed by } \\
\text { learners and time spent on each item; } \\
\text { navigation paths of learners within } \\
\text { the system } \\
\text { - Additional analytics and visualization } \\
\text { tools generated data }\end{array}$ \\
\hline $\begin{array}{l}\text { Learning support } \\
\text { staff }\end{array}$ & $\begin{array}{ll}- & \text { Technical support } \\
- & \text { User support services } \\
- & \text { Monitoring student academic } \\
& \text { and learning progress }\end{array}$ & 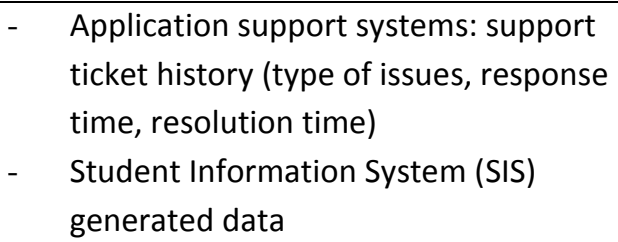 \\
\hline $\begin{array}{l}\text { Administration staff } \\
\text { (Student Affairs) }\end{array}$ & $\begin{array}{ll}- & \text { Student progress } \\
\text { - } & \text { Student flow-through } \\
\text { - } & \text { Student intervention (at-risk } \\
& \text { students) } \\
\text { - } & \text { Retention strategies }\end{array}$ & 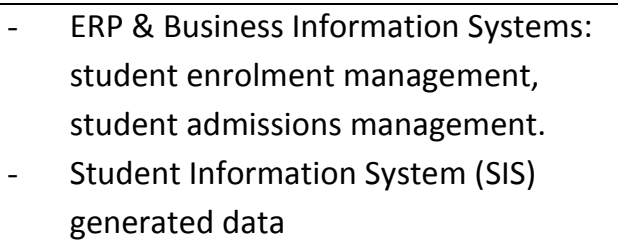 \\
\hline
\end{tabular}

Table 2 categorizes different sets of learning analytics data sources, usages, and stakeholders with varying concerns and expectations from what learning analytics data can offer as information assets. Given that the drivers for acquiring, interpreting, and using learning analytics data for decision-making purposes can vary from one group of stakeholders to another, what one learning analytics stakeholder might perceive as a value-added act, in using learning analytics data, another might perceive as a threat. Consequently, for increasing the chances of success for a learning analytics initiative, a learning analytics data governance model that narrows down the zones of potential conflict among the stakeholders and ISSN 1929-7750 (online). The Journal of Learning Analytics works under a Creative Commons License, Attribution - NonCommercial-NoDerivs 3.0 Unported (CC BY-NC-ND 3.0) 
(2014). Critical Factors in Data Governance for Learning Analytics. Journal of Learning Analytics, 1(3), 211-222.

increases the shared common-ground perspectives on the added value of learning analytics is essential. Supporting the creation of such learning analytics data governance requires that we define the critical factors for consideration when creating the governance model.

\section{CRITICAL FACTORS AND SUGGESTIONS FOR A WAY FORWARD}

Three fundamental common challenges cut across learning analytics data governance models. These are the ownership of the learning analytics data, its interpretation, and the enacting of decisions (evidencebased decision making) based on this learning analytics data. ${ }^{5}$

1. The first challenge with learning analytics data governance modelling is the ownership of the data, which is inherently a distributed ownership. For example, the instructional designer and/or faculty can own the learning process data (depending on the business processes and procedures in place). The Learning and Content Management System (LCMS) team (in some institutions) can own part of the processes and procedures for configuring and collecting the user and usability data. The administrative staff owns part of the learner educational experience data as stored in ERP systems and CRM systems. At any moment, data may not be shared in a timely or adequate manner across these groups of stakeholders for various institutional, procedural, privacy, or ethical reasons.

2. The second challenge is the interpretation of the learning analytics data. Ideally, the type of data sets mined for learning analytics is driven by the learning vision and strategies of the institution. The interpretation of the learning analytics data is also driven by the same vision. However, who/which entity owns the descriptive and predictive interpretations of the learning analytics data is not always clear. For example, who has the first say in making sense of the learning analytics data? Based on which hypotheses and sense-making methods? Who proposes the hypothesis and based on what (business vs. operational vs. educational) drivers? Who designs and interprets the ethical guidelines for gathering, using, and purging such data? In the absence of well-defined hypotheses and sense-making methods, the learning analytics data may not be valuable and might even be controversial, resulting in a push to create organizational silos.

3. The third challenge is the "evidence"-based decision making grounded in learning analytics data. The decision making process can be based on personal, intuitive, accumulated experience, and expertise of the individual/entity making the decision. However, critical decisions with a lower margin of error in judgment require facts-based analysis and controlled testing of possible solutions. Decision making at the level of learning analytics can be critical, as decisions at this level can affect the budgets, operations, and educational reputation of the institution. This

\footnotetext{
${ }^{5}$ There are various ethical and privacy challenges associated with the use of learning analytics data. I will leave these aside as they are beyond the scope of this paper. See Slade and Prinsloo (2013) and their references for a detailed overview and analysis of the ethical issues in learning analytics. 
(2014). Critical Factors in Data Governance for Learning Analytics. Journal of Learning Analytics, 1(3), 211-222.

challenge, of course, is not exclusive to the domain of learning analytics. What is exclusive, however, is that the implementation of learning analytics and its related constraints inherently impose on the leadership an increase in transparent collaboration and openness (Siemens, 2010). This is necessary so that the leadership can carefully integrate the ethical, cultural, political, educational, and entrepreneurial dimensions of learning analytics (Hrabowski, Suess, \& Fritz, 2011; Diaz \& Fowler, 2012).

These three fundamental challenges represent clusters of factors that require careful handling within the confines of a data governance model that represents, protects, and promotes the interests of all the key stakeholders in learning analytics data governance. The following are suggestions for supporting the process of modelling data governance for learning analytics:

1. Starting on a small scale: Some of the stakeholders identified in Table 2 may be skeptical and reserved about the added value of learning analytics. If an institution starts the implementation of learning analytics data governance on a large scale, this may cause serious disruption to the existing structures of governance, business processes, and procedures and, as such, the implementation of learning analytics data governance may defeat the purpose. Evolution works in small steps, and phasing in the model in incremental steps would insure proper adaptation to the existing constraints.

2. Supporting and empowering the key stakeholders: Much of the governance design deals with structures of control, power, and accountability (Slade \& Prinsloo, 2013). It is crucial for the success of the learning analytics data governance to identify, support, and empower key business, educational, and technical representatives. Learning analytics is a cross-organizational endeavour that requires unprecedented collaboration and presupposes the integration of data, sense-making methods, and knowledge at horizontal and vertical levels of the organization. As such, the implementation of learning analytics may require a shift in the organizational culture (Macfadyen \& Dawson, 2012), demanding more transparency and open collaboration. In this respect, as Siemens (2010) notes, "openness produces more of itself."

3. Learning analytics data sets (as information assets) are living dynamic evolving entities: The modelling of data governance for learning analytics needs to consider that if the information emerging out of learning analytics is not circulated to the concerned stakeholders on time, there is a risk of a gap in the information relevance for stakeholders. The moment an information asset (data set) is created, processed, and used can influence decision making at different levels. The learning analytics information use process should be well defined and contain adequate controls, including quality assurance, production, and delivery time of the information assets to different stakeholders of learning analytics.

4. Distribute power structures for learning analytics data governance: Parts of the governance entities (person, department, committee, council) that own the technology infrastructure used 
(2014). Critical Factors in Data Governance for Learning Analytics. Journal of Learning Analytics, 1(3), 211-222.

for harvesting learning analytics data should not be the same ones that define the data sets to collect. Nor should it be the same governance entity that has the privileges of acting on the insights extracted from the learning analytics data.

5. Conflict management and power struggle: The learning analytics data governance model should provide a listing of sanctioned standards that serve as operating principles for handling exceptions, conflicts, metrics, and reporting regarding learning analytics data and its quality. Potential conflicts within the context of learning analytics data governance are a divergence of technical, business, administrative, research, and educational opinions about the definitions, requirements, and processes and procedures for collecting and using learning analytics data sets.

6. Shared understanding of the levels of learning analytics data governance maturity: The stakeholders within the context of learning analytics data governance would need to share the same understanding regarding the status and maturity of the data governance model adopted. Assessing the maturity of learning analytics data governance can be modelled along the lines of the practices of the data management maturity model, which adopts the following sequential phases: non-existent, initial, defined, managed, and optimized governance (Otto, 2011; Norris \& Baer, 2013). This shared understanding about the maturity of learning analytics data governance is necessary to manage the expectations of different stakeholders.

7. Ethical and legal requirements: Some of the stakeholders identified in Table 2 may generate or use learning analytics data subject to legal and ethical restrictions. As such, it is necessary that the learning analytics data governance model allows for a shared understanding of the ethical and legal aspects of using the data (see Slade \& Prinsloo, 2013, and their references).

These suggestions can be taken as high-level requirements that are meant to lend themselves to different contexts of higher education, and ensure that learning analytics data governance modelling is about specifying the decision rights and accountability framework to encourage desirable behaviours in the use of learning analytics data sets.

\section{CONCLUSION}

The three types of learning analytics data governance challenges discussed above highlight the complex and fluid nature of the learning analytics data governance modelling. The basic requirement for creating a learning analytics data governance model is finding sensible solutions to these three challenges in a way that speaks to how resources of learning analytics are secured, how roles and responsibilities are defined, and how accountability is established. Doing so can ensure that the modelling of data governance for learning analytics is approached as an evolving business and educational strategy that requires continuous alignment with the strategic, business, and educational goals of the institution. 
(2014). Critical Factors in Data Governance for Learning Analytics. Journal of Learning Analytics, 1(3), 211-222.

While this approach can address some of the fundamental challenges of data governance for learning analytics, this remains but one modular part of a comprehensive governance model for learning analytics. The development of a comprehensive and adaptive governance model for learning analytics requires that data governance in learning analytics be integrated with learning analytics sense-making frameworks and also with learning analytics ethics frameworks.

\section{REFERENCES}

Alfred, R. (1998). Shared governance in community colleges. Education Commission of the States, 1-8.

Baepler, P., \& Murdoch, C. J. (2010). Academic analytics and data mining in higher education. International Journal for the Scholarship of Teaching and Learning, 4(2), 1-9.

Bichsel, J. (2012). Analytics in higher education: Benefits, barriers, progress, and recommendations. Research Report, EDUCAUSE Center for Applied Research.

Brown, M. (2011, April). Learning analytics: The coming third wave. Retrieved from http://www.educause.edu/library/resources/learning-analytics-coming-third-wave

Campbell, J. P., Deblois, P. B., \& Oblinger, D. G. (2007). Academic analytics: A new tool for a new era. EDUCAUSE Review, 42(4), 41-57.

Chatti, M. A., Dyckhoff, A. L., Schroeder, U., \& Thüs, H. (2012). Learning analytics: A review of the state of the art and future challenges. International Journal of Technology Enhanced Learning, 4(5/6), 318-331.

Davenport, T. H., Harris, J. G., \& Morison, R. (2010). Analytics at work: Smarter decisions, better results. Boston, MA: Harvard Business Publishing.

Diaz, V. \& Fowler, S. (2012). Leadership and learning analytics (ELI Brief). Louisville, CO: EDUCAUSE Learning Initiative. Retrieved from http://net.educause.edu/ir/library/pdf/ELIB1205.pdf

Drachsler, H., \& Greller, W. (2012). The pulse of learning analytics understandings and expectations from the stakeholders. LAK'12 Conference Proceedings. Vancouver, BC, Canada.

Ferguson, R. (2012). Learning analytics: drivers, developments and challenges. International Journal of Technology Enhanced Learning, 4(5/6), 304-317.

Gill, M. (2002). Building effective approaches to governance. Non-Profit Quarterly, 9(2). Retrieved from nonprofitquarterly.org

Greller, W., \& Drachsler, H. (2012). Translating learning into numbers: A generic framework for learning analytics. Educational Technology \& Society, 15(3), 42-57.

Hrabowski, F. A., Suess, J., \& Fritz, J. (2011). Assessment and analytics in institutional transformation. EDUCAUSE Review, 46(5), 14-16

Jones, G. A. (Ed.). (1997). Higher education in Canada: Different systems, different perspectives. NY: Garland Publishing.

Kruse, A., \& Pongsajapan, R. (2012). Student-centered learning analytics. Retrieved from https://cndls.georgetown.edu/m/documents/thoughtpaperkrusepongsajapan.pdf

Long, P., \& Siemens, G. (2011). Penetrating the fog: Analytics in learning and education. EDUCAUSE Review, 46(5), 30-32. 
(2014). Critical Factors in Data Governance for Learning Analytics. Journal of Learning Analytics, 1(3), 211-222.

Macfadyen, L. P., \& Dawson, S. (2012). Numbers are not enough: Why e-learning analytics failed to inform an institutional strategic plan. Educational Technology \& Society, 15(3), 149-163.

Norris, D., \& Baer, L. L. (2013). Building organizational capacity for analytics. Educause Report. Retrieved from http://www.educause.edu/library/resources/building-organizational-capacityanalytics

Otto, B. (2011). A morphology of the organization of data governance. Proceedings of the European Conference on Information Systems, 9-11 June 2011, Helsinki, Finland.

Petersen, R. J. (2012). Policy dimensions of analytics in higher education. EDUCAUSE Review, 47(4), 4449.

Redman, T. C. (1998). The impact of poor data quality on the typical enterprise. Communications of the ACM, 41(2), 79-82.

Romero, C., \& Ventura, S. (2006). Educational data mining: A survey from 1995 to 2005, Expert Systems with Applications, 33, 2007.

Slade, S., \& Prinsloo, P. (2013). Learning analytics: Ethical issues and dilemmas. American Behavioral Scientist, 57(10), 1509-1528.

SOLAR (Society for Learning Analytics Research). (2011, July 23). Open learning analytics: An integrated and modularized platform [Concept paper]. Retrieved from http://solaresearch.org/OpenLearningAnalytics.pdf

Stiles, R. (2012). Understanding and managing the risks of analytics in higher education: A guide. Retrieved from http://net.educause.edu/ir/library/pdf/EPUB1201.pdf.

Siemens, G. (2010). How data and analytics can improve education. Retrieved from http://radar.oreilly.com/2011/07/education-data-analytics-learning.html

Siemens, G., \& Baker, R. (2012). Learning analytics and educational data mining: Towards communication and collaboration. In S. Buckingham Shum, D. Gašević, \& R. Ferguson (Eds.), LAK '12: Proceedings of the 2nd International Conference on Learning Analytics and Knowledge (252254). New York, NY: ACM.

van Barneveld, A., Arnold, K. E., \& Campbell, J. P. (2012). Analytics in higher education: Establishing a common language, ELI Paper 1, EDUCAUSE. Retrieved from http://net.educause.edu/ir/library/pdf/ELI3026.pdf

Weber, K., Otto, B., \& Österle, H. (2009). One size does not fit all: A contingency approach to data governance. ACM Journal of Data and Information Quality, 1(1), 1-27. 